\title{
SPEAKING DIFFICULTIES OF PHILIPPINE INDIGENOUS LEARNERS IN ENGLISH SEMANTICS
}

\author{
Adelaila J. Leaño ${ }^{1}$, Norfishah Mat Rabi ${ }^{2} \&$ \\ Grace Annammal Gnana Piragasam ${ }^{3}$ \\ Faculty of Teacher Development, Philippine Normal University North Luzon, \\ Aurora, Alicia, Isabela, Philippines ${ }^{1}$, \\ Department of Special Education, Faculty of Human Development, \\ Universiti Pendidikan Sultan Idris, Tanjong Malim, Perak, Malaysia ${ }^{2,3}$ \\ leano.aj@pnu.edu.ph ${ }^{1}$,norfishah@fpm.upsi.edu.my²,grace@fpm.upsi.edu.my ${ }^{3}$ \\ DOI: https://doi.org/10.37134/saecj.vo18.no2.2.2019
}

Received: 10 July 2019; Accepted: 30 October 2019; Published: 25 November 2019

\begin{abstract}
This study aimed to investigate Philippine indigenous learners' speaking difficulties in English Semantics. The objectives was to identify indicators of poor vocabulary, processing and expressing of information. It was a qualitative research through case studies of five Grade 2 Indigenous Peoples (IP) learners in Echague, Isabela, Philippines. Data collection was done through observation and oral assessments activities. Instruments include checklist of speaking difficulties signified by inadequacy in English vocabulary; and constructed oral assessment activities in English. Data gathered were qualitatively analysed. Findings revealed that all the five indigenous learner-participants demonstrated English vocabulary deficiency to name depicted objects in the surroundings. They had struggles in reciting week-days, months and in citing common Philippine events. They had difficulty in conveying illustrated antonyms and synonyms. These findings denote a language intervention to improve essential skills in English semantics. This study can be an alternative to investigate problems in other language literacy domains.
\end{abstract}

Key Words: Speaking difficulties, indigenous learners, English language, English vocabulary, processing and expressing of information

\section{INTRODUCTION}

In advancing quality education (Ball, 2011), it has always been a challenge of any country's educational policy to decide on and recommend the right language/s that must be used in instruction. Language of instruction, whether inside or outside the classrooms denotes the language used for teaching the basic curriculum of the educational system. Some countries decide to use one language causing learners who are mother tongue speakers at a remarkable disadvantage in the educational system as in they are receiving instruction in a foreign official language. Nevertheless, other nations opted to use educational strategies that regard national or indigenous languages to be put in place in instruction (UNESCO MotherTongue Based Bilingual Multi-Lingual Education, 2016). In the advent of global political transformation and evolutions, language as a primary right was expressed among the Indigenous Peoples claims.

As education curriculum changed in the Philippines, teaching approaches needed to be transformed. Every Kindergarten to Grade 12 Curriculum strand requires learners, indigenous or non-indigenous, to acquire mastery of lessons as they go through different educational levels (Department of Education, 2016). Teachers of mainstream classrooms in 
the Philippines need to give attention on the aspects of quality language teaching and consider customized educational programs such as intervention to become a part of their pedagogical practices. To make learning possible, teaching approaches and learning activities need to consider components among the three facets: academic excellence, quality learning environment, and impacts (Hanlen, 2010).

For pupils from Kindergarten to Grade 3, teachers may shift to the learner's mother tongue from English or Filipino languages as medium of instruction. This is to guarantee that quality education in the early years may be achieved. This is stipulated in Philippine Department of Education Order No. 74, series of 2009 or the Institutionalization of MTBMLE in the Early Childhood Education in the Philippines (Department of Education, 2009). As such policies in language of instruction are carried out, teachers need to support enrichment of curriculum and assessment strategies that decrease inequalities in language learner's achievements. Furthermore, school and home must provide opportunities that enable disadvantage English language learners to catch up and obtain crucial learning skills and meet the demands of language and communication such as skills in speaking. Hence, for IP learners, schools are compelled to teach the national curriculum in a language they can easily understand (EFA-GMR, 2016; \& Ball, 2011).

Speaking is crucial in the total language development of IP learners. It is simultaneously performed while learner listens (Academia, 2016). To achieve learning, indigenous or non-indigenous learners, are expected to acquire English vocabulary building skills to maximize their learning capabilities through speaking. Their speaking vocabularies in English facilitates sharing of thoughts verbally and help them maintain good academic performance. However, most IP learners and their families may have limited awareness and inadequate competence as an effect of the past failure of the educational system that could have addressed social, linguistic/verbal, cultural needs in teaching and learning. Research uncovered that while reforms are taking course in Philippine education, teachers, parents and learners are challenged regarding languages of instruction. Filipino indigenous learners continuously experience difficulty while English is being utilized as language medium. It is a problem when the indigenous learner is hard up recalling, articulating and interpreting English words. Hence, s/he struggles during classroom interactions.

An issue in the mainstream classes in the Philippines is teachers' preparation. A reason that teachers failed in the past is because they were not prepared in handling indigenous learners with learning problems particularly difficulty in speaking English. They feel that the classroom challenge is very extensive and how or where to start is unclear. These issues were discussed in the Thematic Paper towards the preparation of the 2014 World. Conference on Indigenous Peoples "Education and Indigenous Peoples: Priorities for Inclusive Education" of the Inter-Agency Support Group on Indigenous Peoples' Issues (2014). Much effort has been taken along these issues, by developing specially tailored pedagogical approaches, culturally and linguistically customized learning programs in English for indigenous learners. Noted and emphasized is a need to craft instructional programs such as intervention which are suited to those indigenous learners with learning problems. Furthermore, it was also suggested that to make the said program effective, it must be localized. It must be done in a bottom-up manner to guarantee that infrastructure, materials and instructions, cater the context and unique needs of indigenous learners. However, most of the current instructional programs, materials and assessment processes in the Philippines are more focused on the reading, writing and listening areas not on speaking. In the evaluation of language skills, activities in the speaking domain are generally limited. These are generally carried out through written forms of assessments.

Research evidences impels a gargantuan amount of benevolence among Filipino teachers who are handling indigenous learners with speaking difficulties in English. These 
learners' inadequacies may generate troubles with understanding, acquiring vocabulary and interactions using English language. The challenge is how to help them attain their potentials in academics. The Understood Team (2016) mentioned that some children can have more than one among these obstacles, which are: 1) expressive language difficulties, 2) mixed receptive-expressive language difficulties, and 3) social communication difficulties. During teaching and learning processes, verbal language difficulty in English makes it hard for the child to put his or her ideas even feelings into words. Their vocabulary in English is very limited that they may leave out key words in their sentences and may say sentences with confusing ideas. Some indigenous learners may also manifest difficulty in English when they find it so hard to understand what the teacher is saying and are troubled processing information and expressing thoughts into spoken words. Indigenous learners are much more confronted with orally presented stories that have longer sentences because of poor vocabulary in English.

Another challenge is the Bilingual Policy in the Philippines using both Filipino and/or English as the languages of instruction (Department of Education, 1987). This may academically confront an indigenous learner with problems in speaking because his or her dialect at home is Tagalog. Aside from personal issues in speaking the English language, an indigenous learner faces hardships in grasping lessons and expressing himself or herself in the classroom. Moreover, indigenous learners who are confronted with language complication in English may have problem in processing information, difficulty in sustaining one's span of attention and struggles in focusing during instructions. If speaking difficulty in English persists among Filipino indigenous learners, this may lead to other academic issues and concerns in other areas such as mathematics, Science and Technology.

In language instruction, English takes a very significant role in shaping functional vocabularies among Filipino learners. Semantics refers to the study of meanings of words or phrases based on a specific context. Skills in Semantics language describe the ability to perceive and state labels; and the competence to recognize and name exact brands or categories. It means one's capacity to decipher and tell words and their functions. Moreover, it is the individual's capability to understand and use descriptive expressions including parts of a whole (Children's Speech and Language Services, 2016). English semantics needs to be strengthened among indigenous learners to enable them to cope with their academic struggles and daily school experiences.

This study therefore, aimed to identify speaking difficulties of indigenous learners in English semantics. Specifically, it was intended to determine specific indicators of poor English vocabulary development, and poor information processing and expressing using verbal language.

\section{Literature Review}

Speaking most of the time is unplanned, changing, and flexible. The manner and sense of speaking rely much on situation where it happens; who are involved including their purposes; familiarities, and understandings (Centre for Applied Linguistics, 2016). When the child feels something, she or he likes to tell to somebody who will listen to him or her. Each time the child communicates, she or he produces a message that must have a meaning. In the communication process, it is assumed that the child understands what she or he is talking about so that interaction will take place.

Some indigenous learners have deprivations in speaking English and do not show the willingness to communicate because of so many factors. This disposition to interconnect is a prerequisite to overcome English language barriers (Morozova, 2013). Most of the time, these children have the idea in their minds but they cannot find the term to express the notion. 
This may be related to Word-Finding difficulties (Bator, 2016) and the child feels that the utterance is just on the tip of his or her tongue, but these thoughts could hardly come out as expressions. The child may feel that she or he knows exactly what that word is but the moment she or he says it, it comes out as the wrong one based on his or her thoughts. Recalling the precise name that communicate the idea in the mind of the indigenous learner is very hard for him or her (Coleman, 2014).

Recently conducted research in Russia (Morozova, 2013) gleaned the general problems of Russian students associated with learning to speak were subdivided into four main groups: 1) Students are ashamed to verbalize English because of being afraid to commit errors and being censured by teachers and others. 2) Working in groups which encourages students to use their native language. 3) Students deficiency in information about topics being discussed even in their native tongue. 4) Students seem to be inadequate with language command in solving assigned tasks.

Aside from those concerns in academics, indigenous learners are also challenged with other difficulties and various experiences that are related to their hardship in expressing themselves in a language which majority speaks. Having a very limited exposure to English language impacts their rightful opportunities. Some of legitimate process problems (Australian Law Reform Commission, 2016) confronts indigenous learners particularly in Australia. Their English language limitations and/or cultural barriers that include their mannerism and poor comprehensions, intensify their troubles related to involvement with official processes. Besides speaking difficulties of the indigenous learners in Australia, other concerns that significantly distress them during legal processes comprise obstructions to contact, lack of understanding, ostracism and agency complications. They are overrepresented in those lawful procedures and this have connections with unfavourable results.

Hafiz Ahmad Bilal, Abdur Rehman, Ch. Abdul Rashid, Rana Adnan and Muneer Abbas (2013) noted further that the speaking skills of students is at a frustration level because the educational system of the country centres on reading and writing skills only. Even secondary students, after 8 to 10 years of schooling, are unable to speak English reasonably. Documented setbacks in speaking English as L2 include not enough vocabulary; poor listening skills; effect of L1's (Punjabi) dominance and insufficient access to setting that may provide for speaking of English at home or in school.

In connection to verbal language, important aspects of proper communication such as pronunciation, vocabulary and grammar should not be taken for granted. It was also conferred that verbal language structure is vital and must be learnt first. For Thais, verbal communication turn out to be the most challenging aspect of learning the English language. Based on research findings, there are some reasons why Thais could hardly learn to speak English. In the process, most Thais cogitate in Thai while speaking in English. As a result, they think in Thai then translate these thoughts into English. In addition, there is much concern on pronunciation since English Alphabets are articulated in varied ways. Thai students focused more on grammar rather than on the communicative facets of English language. It was deliberated that there is a need to look for highly efficient ways to facilitate learning of the English among Thai students and limit or eliminate concerns like insufficient practice in pronunciation. Observance of grammatical structure is further encouraged among Thai students and to discover strategies to master English vocabulary (Faculty of Education, 2014).

In the same research article, some other problems affecting English fluency among Thai students were expounded. Many of them consider English language learning as an extra additional academic activity and of minor importance as compared to other subjects like math, science, and so on. Thai students in the primary school are not interested to learn English until such time that they reach high school and deem English as a part of their career. 
It was also noticed that many Thai student keep away from foreign language interactions even with electronic or paper channels. They are not attracted with foreign cultures and they do not indulge in any conversation that involve English as a medium in their daily life (Faculty of Education, 2014).

In the study conducted by the (Gan, 2012) insufficient vocabulary in English was found out to be a predominant problem among students. This was seen as the main reason why sometimes students are hard up expressing themselves vividly and correctly. Students likewise thought of that this influenced their fluency in their speech. Another noted cause of oral language deficiency of students is scarcity of chances to speak English in class. Most of the lectures are typically didactic and teaching approaches are programmed. Hence, it is expected that little interaction like small-group activities and in-class questioning are anticipated. It is further reported that adeptness in English has been considered among Hong Kong Chinese as main element of rising and apparent progress. Most business corporations in Hong Kong favoured employees with better English language command than Chinese. However, in Hong Kong, Cantonese is the leading language. So, English as a language in Hong Kong is often regarded as input-poor environment as most interaction or conversation outside English classes is in Cantonese making English seldom used in social exchanges. (Gan, 2012).

Various types of investigations were conducted as regards English semantics, which are focused on vocabulary development and information processing aspects. Ebrahimi (2017), embarked on measuring productive depth of vocabulary knowledge of the most frequent words. This study emphasized abilities in writing and speaking, which are very important for students in learning English for academic functions. These students are encountering struggles with oral expression during presentations of written assignments (Evans \& Green, 2007). The research project concentrated on four facets of vocabulary elements such as: word parts, relationships, comparisons, and meaning and structure. Each research component was provided with equivalent productive tests. One test of word parts, two tests of semantic associations (synonym \& antonym, and superordination \& subordination tests), one test of collocation, and four corresponding productive tests of formmeaning connection. It was uncovered that students' awareness of collocations and on word parts was somewhat lower. Although, they manifested a better functioning on form meaning association, superordination and subordination.

Similar studies were accomplished of Chen \& Truscatt (2010), \& Pigada \& Schmitt (2006), Webb (2005, 2007a, 2007b, 2007c, 2009a, 2009b). Research findings lead to profitable multi-dimensional successions of tests for its measurement. Nonetheless, no inquiries have been performed that gauge the intensity of comprehension of the most common words.

\section{METHODOLOGY}

This is a qualitative research. According to Creswell (2013), qualitative study is a technique of discovering and perceiving important attributes of individuals or groups in relation to social or human concern. In the conduct of the investigation, case studies were carried out through transpiring inquiries and processes. Purposive sampling was utilized with the five Grade 2 Indigenous Peoples (IP) learners from the Yogad tribe in Tuguegarao-Sto. Domingo Elementary School, Echague, Isabela, Philippines. The teacher-participant was selected on a voluntary basis. She was the class adviser and teacher in English. From among the indigenous learners, teacher recommended the five indigenous learners with consideration to 
parents/guardians' decisions. These were Grade 2 pupils who are experiencing difficulties in speaking English related with semantics.

Data collection involved observation, supervision of oral assessment in English semantics, interview and document analysis. The descriptions of entire collection of the indigenous learner's problems that are related to poor English vocabulary and expressions, served as baseline for the crafting of Instruments. These comprised the checklist of speaking difficulties in English semantics and constructed oral assessment. These speaking difficulties of indigenous learners in English were re-aligned with Kindergarten to Grade 12 Curriculum Guide in English for Grade 2 (Department of Education, 2016). Instruments were subjected to validation of experts in the curricula of Language, Special Education, and Indigenous Peoples Education (IPEd) in the Division of Isabela, Department of Education-Philippines. In the administration of the oral assessment activity, it was made sure that every item for oral activity, including the directions were correlated to each recorded speaking difficulty of indigenous learners in English. Separately, teacher-participant and the researcher engrossed each indigenous learner in oral assessment activities to find out their specific speaking difficulties in English semantics.

Data analysis involved identification of speaking difficulties that confronted the indigenous learners. Furthermore, document analysis regarded how the indigenous learner responded to assessment materials and technologies. These centred on the concrete manifestations of speaking difficulties through checklist results and audio-recordings during oral assessment activities of every indigenous learner.

\section{RESULTS}

Semantics refers to the study of meanings of words or phrases based on a specific context. Skills in Semantics language refer to the ability to perceive and state labels; and skill to identify and name exact brands or categories. It involves the capacity to decipher words that may include telling their functions; and the skills to understand and use descriptive words including parts of a whole (Children's Speech and Language Services, 2016). The findings refer to the speaking difficulties of indigenous learners in English semantics that covered speaking difficulties in (i) English vocabulary development, and (ii) processing and expressing of illustrated information in English.

\section{Speaking difficulty indicated by poor vocabulary development in English}

English vocabulary is essential for the Philippine indigenous learners to enable them to verbalise their comprehension of familiar English words and for effective communication. They should be able to demonstrate orally their interpretation of word meaning for appropriate conversation habits using English.

Table 1 presents the findings that majority of IP learners were poor in English Vocabulary based on the oral assessment activity conducted by the researcher and their teacher. Data from both assessments showed that all the five IP learners cannot verbally cite objects that are typically found in their surroundings using English. They could hardly articulate English words to convey ideas about oneself, personal belongings and about one's environment even if these objects are concretely presented, shown in pictures and/or through animations. They cannot mention the days and months including important dates and Philippine events in English. They were hard-up in giving the corresponding antonyms or opposites and synonyms or parallels despite given illustrations of English words. 
In details, the researcher assessed that indigenous learner- 3 is unable to say English expressions to communicate simple ideas indicated in signs, symbols and signage. Their teacher confirmed the same difficulty as the struggle of indigenous learners 3 and 4 in speaking English language. Teacher did not find internalising months of the year or other related details or important dates and events as a difficulty of indigenous learner 1 . However, researcher deemed this as shortcoming of this indigenous learner. Nevertheless, both concluded that only indigenous learner 5 faced hardship in determining colours of common objects or items (e.g., Philippine flag, plants, animals, fruits, school items, etc.)

Table 1Speaking difficulties of Indigenous Peoples (IP) learners in English vocabulary development

\begin{tabular}{|c|c|c|}
\hline Poor Vocabulary Development Indicators & $\begin{array}{l}\text { Teacher's } \\
\text { Assessment }\end{array}$ & $\begin{array}{l}\text { Researcher's } \\
\text { Assessment }\end{array}$ \\
\hline $\begin{array}{l}\text { Struggle in telling the English words for objects commonly found in the } \\
\text { environment shown in pictures. }\end{array}$ & IL- $1,2,3,4 \& 5$ & IL- $1,2,3,4 \& 5$ \\
\hline $\begin{array}{l}\text { Inability to give common name for given nouns (i.e., persons, body } \\
\text { parts, plants, animals, places, and things) shown in pictures. }\end{array}$ & IL- $1,2,3,4 \& 5$ & IL- $1,2,3, \& 5$ \\
\hline $\begin{array}{l}\text { Hardship in determining colours of common objects or items (Philippine } \\
\text { flag, plants, animals, fruits, school items, etc.) }\end{array}$ & IL- 5 & IL- 5 \\
\hline $\begin{array}{l}\text { Incapacity to use English word/expressions to communicate simple ideas } \\
\text { indicated in signs, symbols and signage. }\end{array}$ & IL- 3 & IL- $3 \& 4$ \\
\hline $\begin{array}{l}\text { Incompetence to respond to cues in recalling and reciting the days of the } \\
\text { week or other related details or important dates and events. }\end{array}$ & IL- $1,2,3,4 \& 5$ & IL- $1,2,3,4 \& 5$ \\
\hline $\begin{array}{l}\text { Difficulty in internalising months of the year or other related details or } \\
\text { important dates and events. }\end{array}$ & IL- $1,2,4 \& 5$ & IL- $2,4, \& 5$ \\
\hline $\begin{array}{l}\text { Troubles in responding to semantic cues when recalling and giving a } \\
\text { corresponding antonyms of a given simple word. }\end{array}$ & IL- $1,2,3,4 \& 5$ & IL- $1,2,3,4 \& 5$ \\
\hline $\begin{array}{l}\text { Struggles in responding to semantic cues when recalling and giving a } \\
\text { corresponding synonyms of a given simple word. }\end{array}$ & IL- $1,2,3,4 \& 5$ & IL- $1,2,3,4 \& 5$ \\
\hline
\end{tabular}

IL - Indigenous Learner

\section{Speaking Difficulties in Processing and Expressing Understanding of Information in English}

The Minimum Learning Competency (MLC) requires Filipino English learners to acquire the ability to use basic vocabulary to interpret correctly and express independently their thoughts about personal, home, school and community experiences. In this connection, they are assumed to suitably utilise familiar words in speaking activities (Department of Education, 2016). In this investigation, there were noted speaking difficulties of Filipino indigenous learners that may hinder their learning to interact effectively in oral activities in English and may negatively affect their academic performance. Table 2 gleaned all these problems in processing and expressing of understanding of information in English.

Table 2 Speaking difficulties in processing and expressing of illustrated information in English

\begin{tabular}{lll}
\hline Indicators & Teacher's & $\begin{array}{l}\text { Researcher's } \\
\text { Assessment }\end{array}$ \\
\hline Incompetence to describe feelings of persons in pictures. & Assessment & IL-1, 2, 3, 4 \& 5
\end{tabular}


Inability to use English language to express his or her interpretations of the messages of persons in pictures.
IL-1, 2, 3, 4 \& 5

IL-1, 2, 3, 4 \& 5

Incapability to find proper English expressions to respond to the message of the person in a picture.

Helplessness to express depicted information such as situations, action or task using English.

Hardship to articulate what and wherefores of things in English word/s.
IL-1, 2, 3, 4 \& 5

IL-1, 2, 3, 4 \& 5

IL-1, 2, 3, 4 \& 5

IL-1, 2, 3, 4 \& 5

IL-1, 2, 3, 4 \& 5
IL-1, 2, 3, 4 \& 5

IL - Indigenous Learner

Table 2 shows the oral assessment of teacher and the researcher on the speaking difficulties of the five indigenous learners in processing and expressing of illustrated information in English. Based from the two isolated oral assessment activities, all the five indigenous learners experienced speaking troubles such as discussing their ideas based on a depicted event in English. These included incompetence in describing feelings of persons as illustrated. They articulate what a character is trying to convey in English, based on the situation that is portrayed. Teacher and researcher contemplated that these indigenous learners are challenged in telling proper English expressions to respond to the need of somebody as shown in a picture. For instance, someone is in pain or in dire need of help, the indigenous learners cannot tell the right English expression to reply to the person's sentiments. They are weak in communicating their thoughts on a represented material such as situation, action or task using English. It was hard for them to tell details of typical objects in English.

\section{DISCUSSION}

Mother Tongue Based Multi-Lingual Education (MTB-MLE) policy in the Philippines provides Indigenous Peoples (IP) language as medium of instruction from KindergartenGrade 3. English is offered as a subject from second semester in Grade 1, onwards (Department of Education, 2012). Although Indigenous Peoples in the research locality speak Yogad, the five indigenous learners speak Tagalog, the local version of the Filipino language, as their Mother Tongue. When MTB-MLE policy is implemented, some Grade 2 pupils in the research locale face problems in learning to speak English. Obviously, every indigenous learner speaks several languages before his or her exposure to English, making it a third language or "another language" to learn. Eventually, the indigenous learner has to deal with difficulties in building vocabulary in English as an academic subject and as a medium of formal oral communication in school.

Vocabulary building usually incorporates recognising of a word that one already know, however, if one failed to identify such word then, poor vocabulary exists. In this study, poor vocabulary development in English is pertained to the indigenous learner's incapacity to articulate English expressions and inability to verbalise his or her comprehension for interaction purposes. This were reflected through his or her lack of confidence in using familiar English vocabulary to express ideas in speaking activities. Messer (2011) agreed that vocabulary problems occur when a learner cannot decipher the meaning of words or expressions being heard or read or had never heard these words before. The vocabulary difficulty in English according to Farnen (2017) is encountered when pair of words sound in the same way but have different or various meanings. This was called false cognates which caused confusion among Spanish students of English; or difficulty grasping the relationship between words in same sort or synonyms (Children's speech and Language Services, 2017). Similarly, Hagan (2010) underscored that inadequate use of English words in the indigenous 
learner's perspective and lack of habit in speaking English resulted to poor vocabulary. Students' spoken language and intellectual capacity flanked by two to three below grade level (Taboada and Rutherford, 2011).

It was summed up that poor vocabulary level in English is a factor that also caused difficulty of acquiring comprehension skills (Understood Team (2016). Parent and teacher should bridge the three languages (Mother Tongue, Filipino and English) of the indigenous learner to facilitate the development of his or her vocabulary in English. This may be carried by using pictures, representations and other contextualized learning fashions. Indigenous learner must regularly be given sorts of stimulating oral and visual activities to increase his or her knowledge and interests to speak in English. Moreover, weeklong/month-long posting of illustrated English vocabulary words with the conduct verbal activities and oral tests may motivate the indigenous learner and help him or her adopt desired terminologies in English.

Assimilating Vocabulary is a vital part of learning a second language since words are the building blocks of a verbal communication (Deng 2015; \& Francis \& Simpson, 2009). Communicative skills, require one's strategic ability that have something to do with verbal and non-verbal techniques for self-correction and increasing efficacy of communication such as distinguishing form of discourse, activating prior knowledge, grasping through the context, and bearing of doubts (Department of Education, 2016).

Poor or slow processing of information and putting into words an illustrated material in English were noted speaking difficulties of indigenous learners in the case studies. Comparably, Glende (2013) stressed that students having hassles with vocabulary, normally combat grasping and obtaining ideas. Rupley \& Slough (2010) underscored that English language learners (ELL) face twofold obstacles such as acquiring a second language, English as channel of teaching and for being responsible in acquiring content and ideas in English. Funaro (2014) highlighted that lack of speaking vocabulary in English impedes learner's adjustment to educational environment and to the next academic ladder. Moreover, ELLs confront complexities with pedagogic text because of inadequate prior subject knowledge, weak verbal language and vocabulary levels that adversely influence academic success (Glende, 2013; \& Denton, Wexler, Vaughn, \& Bryan, 2008). Glende (2013) emphasised that deficiency in academic language normally hinders second language adult learners to recognise and analyse academic texts. These speaking problems in English may be remedied by habitually providing the indigenous learner sorts of stimulating oral and visual activities to increase his or her knowledge and interests to speak in English.

Teachers and parents should provide language intervention program of undertakings, with customized instructional materials, techniques and positive approaches that are in line with vocabulary building in English. Frequently engage indigenous leaners in introducing themselves to formal or informal settings, dyads or small group settings using English expressions. There were studies, which underscored that parent's active involvement in the early years of schooling of their children, may influence children's academic life. In a study titled "Play-based intervention effects on language production in toddlers from a high-risk background" of O'Bleness (2015), an assessment on the use of Child's game, on the language improvements among normally developing toddlers was carried out. It was a play-based, parent- engaged intervention, which was aimed at child obedience and the parent-child relationship, not language production. During the intervention, Child's Game trained mothers to make use of particular play and techniques of communication each time they interact with their child. Toddlers in the study with lesser skills in language production, exhibited farther progress in the areas of total utterances, quantity of distinctive words, total number of words, type-token ratio, and percentage of eloquence. In addition, children who have advanced proficiencies in language production displayed more progress in mean length of utterances. 


\section{CONCLUSION}

Based on the abovementioned findings, it is concluded that indigenous learners in this study were extremely hard-up in articulating their ideas. They had difficulty expressing their feelings on entities around using English since this language is already considered their third language. These speaking problems are due to their very limited engagement with English language most particularly in oral activities. Lacking in early exposure to English language may cause weaker intellectual capacity of indigenous learners in acquiring skills to speak English. Their inadequate vocabulary in English influences their capacity to comprehend the meaning and importance of English words or expressions. Being poor in English vocabulary affects indigenous learners in recognising words in such as a way that they mispronounce or just guess the articulation of English words.

\section{Acknowledgement}

The main author would like to convey her profound gratitude and appreciation to Philippine Normal University and Universiti Pendidikan Sultan Idris, Malaysia for the support to finish this study.

\section{Corresponding Author}

Adelaila J. Leaño

Faculty, Philippine Normal University North Luzon, Philippines

leano.aj@pnu.edu.ph

\section{REFERENCES}

Academia. (2016). Teaching speaking to young learners. Retrieved from http://www.academia.edu/4066131/Teaching_speaking_English to young_learners

Ball, J. (2011). Enhancing learning of children from diverse language backgrounds: Mother Tongue-Based bilingual or multilingual education in the early years. A Paper Commissioned for UNESCO.

Barouni E.A. (2017). Measuring Productive Depth of Vocabulary Knowledge of the Most Frequent Words. Electronic Thesis and Dissertation Repository. Retrieved from https://ir.lib.uwo.ca/etd/4894; https://ir.lib.uwo.ca/etd

Bator, K. (2016). Word-Finding difficulties and strategies. Retrieved from http://www.landmarkoutreach.org/sites/default/files/spotlight/Word-Finding\%20Difficulties.pdf

Center for Applied Linguistics. (2016). What speaking is? U.S. Department of Education (ED), Office of Vocational and Adult Education (OVAE). Retrieved from http://area.dge.mec.pt/gramatica/whatspeakingis.htm; http://www.cal.org/caela/esl_resources/digests/Speak.html

Chen, C., \& Truscott, J. (2010). The effects of repetition and L1 lexicalization on incidental vocabulary acquisition. Applied Linguistics. Retrieved from https://ir.lib.uwo.ca/etd/4894; https://ir.lib.uwo.ca/etd

Children's speech and Language Services (2017). Semantic Language. Retrieved from http://cslstherapy.com/semantic-language/

Coleman, H. (2014). Strategies to support expressive language. Special Needs Jungle by Mantra and \& Word Press. Retrieved from http://www/specialneedsjungle.com/strategies-support-expressive-language/ 
Creswell, J. (2013). Research design: qualitative, quantitative and mixed methods approaches. SAGE Publications, Inc. Thousand Oaks, California.

Deng, Q., \& Trainin, G. (2015). Learning Vocabulary with Apps: From Theory to Practice..The Nebraska Educator: A Student-Led Journal. Paper 29. Retrieved from http://digitalcommons.unl.edu/nebeducator/29

Denton, C. A., Wexler, J., Vaughn, S., \& Bryan D. (2008). Intervention provided to linguistically diverse middle school students with severe reading difficulties. Learning Disabilities Research and Practice, 23(2), 7989.

Department of Education (2009). Institutionalization of Mother Tongue Based-Multilingual Education in the Early Childhood Education in the Philippines. In: Department Order No. 74, series of 2009.

Department of Education (2016). K to 12 Curriculum Guide in English for Grade 1-10. www.deped.gov.ph

Evans, S., \& Green, C. (2007). Why EAP is necessary: A survey of Hong Kong tertiary students. Journal of English for Academic Purposes. Retrieved from https://ir.lib.uwo.ca/etd/4894; https://ir.lib.uwo.ca/etd

Faculty of education (2014). Problem faced by Thai student in speaking English. English language department. The State Islamic Institute of Tulungagung. Retrieved from https://www.academia.edu/9423968/problem faced by thai student in speakingenglish

Farnen, K. (2017). Common English difficulties for ESL Spanish students. Classroom. Retrieved from https://classroom.synonym.com/common-english-difficulties-for-esl-spanish-students$\underline{12081873 . h t m l}$

Funaro, S. (2014). The effects on using ipads in teaching sight words to English Language Learners. Theses and Dissertations. Retrieved from http://rdw.rowan.edu/etd/308

Francis, M. A., \& Simpson, M. L. (2009). Vocabulary development. In R. F. Flippo \& D. C. Caverly (Eds.), Handbook of college reading and study strategy research (2nd ed., pp. 97-120). New York, NY: Taylor \& Francis.

Gan, Z. (2012). Understanding L2 Speaking Problems: Implications for ESL Curriculum Development in a Teacher Training Institution in Hong Kong. Australian Journal of Teacher Education, 37(1). http://dx.doi.org/10.14221/ajte.2012v37n1.4

Glende, L. (2013). Vocabulary and word study to increase comprehension in content areas for struggling readers. Education Masters. Retrieved from http://libguides.sjfc.edu/citations

Hagan, E. (2010). Response to intervention: Implications for Spanish-speaking English language Learners. RTI ACTION NETWORK. Retrieved from http://www.rtinetwork.org/learn/diversity/response-tointervention-implications-for-spanish-speaking-english-language-learners

Hafiz, A., Abdur R., Ch. Abdul R., Rana A. \& Muneer A. (2013). Problems in Speaking English with L2 Learners of Rural Area Schools of Pakistan. Language in India Retrieved from $\underline{\text { www.languageinindia.com }}$

Hanlen, Wendy (2010). Aboriginal students: Cultural insights for teaching literacy. State of New South Wales through the NSW Department of Education and Training, 2010. Retrieved from http://www.curriculumsupport.education.nsw.gov.au/literacy/assets/pdf/packages/ab_studs_cult.pdf

Messer, D. (2011). Reading and child development: Research findings: Putting it together: Letters, sounds and words. Retrieved from http://www.open.edu/openlearn/body-mind/reading-and-child-developmentresearch-findings-putting-it-together-letters-sounds-and-words

Morozova, Y. (2013). Methods of enhancing speaking skills of elementary level students. Retrieved from http://translationjournal.net/journal/63learning.htm 
Pigada, M., \& Schmitt, N. (2006). Vocabulary acquisition from extensive reading: A case study. Reading in a Foreign Language. Retrieved from https://ir.lib.uwo.ca/etd/4894; https://ir.lib.uwo.ca/etd

Rupley, W. H., \& Slough, S. (2010). Building prior knowledge and vocabulary in science in the intermediate grades: Creating hooks for learning. Literacy Research and Instruction. Retrieved from http://libguides.sjfc.edu/citations

Taboada, A., Rutherford, V. (2011). Developing reading comprehension academic vocabulary for English language learners through science content: A formative experiment. Reading Psychology. Retrieved from http://libguides.sjfc.edu/citations

The Understood Team. (2016). Understanding your child's trouble with spoken language. Retrieved from https://www.understood.org/en/learning-attention-issues/child-learning-disabilities/issues-involvingspoken-language/understanding-your-childs-trouble-with-spoken-language

UNESCO. (2016). Children need to be taught in a language they understand. EFA Global Monitoring Report. Retrieved from http://www.unesco.org/new/fileadmin/MULTIMEDIA/HQ/ED/GMR/pdf/language_factsheet.pdf

UNESCO. (2016). Indigenous peoples and UNESCO. Retrieved from http://www.unesco.org/new/en/indigenous-peoples/education-and-intergenerational-transmission

Webb, S. (2005). Receptive and productive vocabulary learning: The effects of reading and writing on word knowledge. Studies in Second Language Acquisition. Retrieved from https://ir.lib.uwo.ca/etd/4894; https://ir.lib.uwo.ca/etd

Webb, S. (2007a). Learning word pairs and glossed sentences: The effects of a single context on vocabulary knowledge. Language Teaching Research. Retrieved from https:/ir.lib.uwo.ca/etd/4894; https://ir.lib.uwo.ca/etd

Webb, S. (2007b). The effects of repetition on vocabulary knowledge. Applied Linguistics. Retrieved from https://ir.lib.uwo.ca/etd/4894; https://ir.lib.uwo.ca/etd

Webb, S. (2007c). The effects of synonymy on vocabulary learning. Reading in a Foreign Language. Retrieved from https://ir.lib.uwo.ca/etd/4894; https://ir.lib.uwo.ca/etd

Webb, S. (2008). Receptive and productive vocabulary sizes of L2 learners. Studies in Second Language Acquisition. Retrieved from https://ir.lib.uwo.ca/etd/4894; https://ir.lib.uwo.ca/etd

Webb, S. (2009a). The effects of pre-learning vocabulary on reading comprehension and writing. Canadian Modern language Review. Retrieved from https://ir.lib.uwo.ca/etd/4894; https://ir.lib.uwo.ca/etd

Webb, S. (2009b). The effects of receptive and productive learning of word pairs on vocabulary knowledge. RELC Journal. Retrieved from https://ir.lib.uwo.ca/etd/4894; https://ir.lib.uwo.ca/etd

Yin, R. K. (2009). Case study research: Design and methods (4th ed.). Thousand Oaks, CA: Sage.

Yin, R. K. (2012). Applications of case study research (3rd ed.). Thousand Oaks, CA: Sage. 